\title{
The Normative Challenge for Illusionist Views of Consciousness
}

\author{
FRANÇOIS KAMMERER \\ FNRS, Université catholique de Louvain, Institut Supérieur de Philosophie, CEFISES
}

\begin{abstract}
Illusionists about phenomenal consciousness claim that phenomenal consciousness does not exist but merely seems to exist. At the same time, it is quite intuitive for there to be some kind of link between phenomenality and value. For example, some situations seem good or bad in virtue of the conscious experiences they feature. Illusionist views of phenomenal consciousness then face what I call the normative challenge. They have to say where they stand regarding the idea that there is a link between phenomenality and value. If they accept that there is such a link, they might be committed to revisionary normative consequences (and some of them may prove to be uncomfortable). If they deny that there is such link, they might avoid revisionary normative consequences (without being guaranteed against them) but then they have to give reasons to deny that such link obtains, which is not a trivial task. The existence of the normative challenge does not show that illusionism is false, but it shows that illusionism might have important consequences in the normative domain, which have to be clarified.
\end{abstract}

\section{Introduction}

Here is an attractive thesis: there is a link between phenomenal consciousness and value. For example, some situations seem good or bad in virtue of the particular phenomenal states they feature. Think about someone being in pain: virtually everyone thinks that this situation is bad. Moreover, it is not only that we think that pain is bad; it seems bad in virtue of its peculiar phenomenal feel. We think pain is bad because it feels awful. Some philosophers have even gone further in asserting the link between phenomenal consciousness and value. They have claimed that nothing, without phenomenal states, can have value. For them, phenomenality is a crucial ingredient to make something - anything! - good or bad.

Contact: François Kammerer <kammerer.francois@gmail.com> 
Illusionists about consciousness claim that phenomenal consciousness does not exist, but merely seems to exist. That puts them in a difficult situation when considering the attractive view that there is a link between consciousness and value: they face what I call the normative challenge for illusionist views of consciousness. They have to say where they stand regarding the link between phenomenality and value. If they accept that there is such a link, they are led to revisionary consequences regarding what has value (more or less radical, depending on the kind of link they recognize). They then need to be clear about how far these consequences extend, and whether they can be limited. If, on the other hand, they deny that there is such a link, they might avoid revisionary consequences regarding what has value. However, they must then give reasons to reject this link, given that it is an attractive thesis. Moreover, even then, their views are not entirely guaranteed against some potential revisionary consequences regarding what has value, and these potential consequences ultimately need to be clarified.

Because each branch of the alternative raises difficulties, I take it that illusionists face a genuine challenge. However, that illusionism faces the normative challenge does not imply that it is false. Whether or not the normative challenge could ever constitute the basis of a robust argument against illusionism is in fact quite debatable. However, we must face up to the fact that illusionism encounters difficulties when one examines its consequences in the normative domain. Illusionists have to live up to this challenge by saying whether (and how) radical revisionary consequences can be avoided. If they cannot be avoided, illusionists have to explain how far exactly these consequences extend-and, ideally, how we can live with them. Besides, some philosophers seem to think that illusionism necessarily has disastrous revisionary consequences in the normative domain. These consequences appear to constitute one of their motivations (though arguably not the only one) to reject illusionism. ${ }^{1}$ This gives illusionists another reason to seriously discuss the consequences of their position in the normative domain.

I intend to show that illusionism does not necessarily have revisionary consequences in the normative domain. However, we would be wrong to think that illusionism can easily avoid all revisionary normative consequences. The most plausible ways to deal with the normative challenge probably lead to some revisionary consequences.

I first give definitions in order to explain what I mean by "phenomenal consciousness", "illusionism" and "value" (§I). I then present two theses, designed

1. See for example what Galen Strawson writes about Dennett's illusionism:

If [Dennett is] right, no one has ever really suffered, in spite of agonizing diseases, mental illness, murder, rape, famine, slavery, bereavement, torture, and genocide. And no one has ever caused anyone else pain [ . . . ] We must hope that [this idea] doesn't spread outside the academy, or convince some future information technologist or roboticist who has great power over our lives. (Strawson 2018). 
to express two versions of the idea that phenomenality is linked to value (\$2). I show why these theses are attractive $(\$ 3)$. I then present the normative challenge for illusionist views of consciousness (\$4). I explore the main options open to the illusionist and I show that all of them create difficulties (\$5-6). I conclude with some remarks about the consequences of the normative challenge $(\$ 7)$.

\section{Definitions}

Phenomenally conscious states (or "phenomenal states", "conscious experiences") are putative mental states endowed with phenomenal properties (or "qualia"), in virtue of which there is "something it is like" to be in them. Seeing a green patch, smelling a rose, feeling pain, are supposed to be typical examples of phenomenally conscious states. A subject who is able to enter into such states possesses phenomenal consciousness. Phenomenally conscious states must be notably distinguished, at least conceptually, from access-conscious states, defined as mental states bearing content available for use in reasoning, and rational control of speech and action (Block 1995). Valenced phenomenal states are "affective" phenomenal states, which are either attractive (positive valence) or repulsive (negative valence). Pain and sorrow are supposed to be typical examples of negatively valenced phenomenal states; pleasure and joy are supposed to be typical examples of positively valenced phenomenal states.

Illusionism about phenomenal consciousness (sometimes also called "eliminativism" 2 - here I do not distinguish between the two) is the thesis that phenomenal consciousness does not exist, but merely seems to exist. For illusionists (as opposed to realists) about phenomenal consciousness, we never enter phenomenal states and there is nothing it is like to be anyone. We simply enter states (introspective states) that incorrectly represent that we are in phenomenal states, thus creating the illusion of phenomenal consciousness. First versions of such views have been suggested in the 1960s (Feyerabend 1963; Rorty 1965); this position has found prominent defenders in the late 1980s (Dennett 1988; 1991; Rey 1995). It has been recently receiving more attention (Dennett 2017; Frankish 2016; Graziano 2013; Pereboom 2011).

Interest for illusionism has been growing fast in the last ten years, probably because it provides a robust (though counter-intuitive) defense of physicalism regarding the human mind - an otherwise very attractive metaphysical position, which has been threatened by arguments and thought experiments focusing on the alleged non-physical nature of phenomenal consciousness (Chalmers 1996;

2. In the framework suggested by Irvine and Sprevak (in press), illusionism as I understand it would be equivalent to entity eliminativism (as opposed to discourse eliminativism). 
Jackson 1982). For many years, most philosophers of the mind have endorsed physicalism but have favored a realist view of consciousness. The most popular position has probably been the one David Chalmers dubbed "type-B" physicalism (Chalmers 2002). According to this view, phenomenal consciousness reduces to physical processes, even though such reduction will forever remain somewhat opaque-in some views, to the point that we should expect consciousness to persistently seem distinct from physical processes (Aydede \& Güzeldere 2005; Balog 2012; Kriegel 2009; Loar 1997; Papineau 2002; Sturgeon 1994). This was supposed to give a way to maintain physicalism about consciousness, while accounting for the persisting difficulties encountered by all attempted reductions of consciousness to some physical process. However, there has been a growing concern that such views cannot ultimately succeed, and that it is impossible to conjoin physicalism about consciousness with a satisfying account of why consciousness seems persistently distinct from the physical (Chalmers 2007; Demircioğlu 2013; Goff 2011; Levine 2001; 2007; Nida-Rümelin 2007). This point is still widely debated (Diaz-León 2014; Elpidorou 2013; 2016; Schroer 2010; Shea 2014), but the idea that we really can "have it both ways" (Loar 1997: 598) - account at the same time for the ontological reducibility of consciousness and for its persistent epistemic irreducibility-seems somewhat less plausible than it once did. For that reason, illusionism, which allows us to defend physicalism about the human mind in a simple (but radical) way, by simply denying that the most problematic aspect of the mind (consciousness) really exists, has been receiving a renewed interest in the last years. Though it remains a minority view, it has found vocal support, both from proponents (illusionism has been described as the "obvious default theory of consciousness", Dennett 2016) and from opponents ("if I were a materialist, I would be an illusionist", Chalmers 2018).

A few things to note. First, what I describe here is what Keith Frankish (2016: 15-16) calls "strong illusionism". Some philosophers have defended a position he dubs "weak illusionism", according to which phenomenal consciousness exists, but does not have many of the properties it is usually thought to have (it merely seems to have these properties). My focus here is on strong illusionism (I will briefly go back to weak illusionism at the end of this paper). Second, illusionists think that there are no phenomenal states in reality. To talk about the real states and properties which are usually thought to be phenomenal, they talk of "quasi-phenomenal" states/properties (as suggested by Frankish 2016: 15). A quasi-phenomenal property is a non-phenomenal, physical property (possibly a wildly disjunctive property), plausibly a brain property, that we typically misrepresent as phenomenal-for example, through introspection. States that have quasi-phenomenal properties are quasi-phenomenal states. According to an illusionist, when I look at a red apple, I have a quasi-phenomenal perception of red, endowed with quasi-phenomenal redness; when I jam my finger in a door 
I enter quasi-phenomenal pain, etc. Third, in order to talk about what happens to me when I look at a red apple or when I jam my finger in a door in a way which remains neutral between illusionism and realism, I will talk of "allegedly phenomenal states/properties". Allegedly phenomenal redness and allegedly phenomenal pain are properties and states that are phenomenal if the realist is right, but merely quasi-phenomenal if the illusionist is right. Fourth, in this paper, I will presuppose that, if we take the set of physical truths about the world as fixed, the existence and the non-existence of phenomenal consciousness are both conceivable. That is, that both zombies and genuinely conscious beings are conceivable, given physical truths about the world. ${ }^{3}$ So, if we are realists about consciousness, we think that we are genuinely conscious beings, but zombies are nevertheless conceivable. If we are illusionists, we think that we are zombies, but genuinely conscious beings are nevertheless conceivable.

Let us turn to value. I will presume that the bearers of value are situations: situations are good or bad. I will also talk of states (i.e., property-instantiations) which can compose situations as grounding value, when situations including these states have such value in virtue of these states being the case. A property, the instantiation of which grounds value, is a "value-making property"; the corresponding state a "value-making state" (A. Lee 2018). A distinction is often made between full and partial grounding (Fine 2012): A grounding B can mean either that B obtains entirely in virtue of $A$ (full grounding) or that B obtains in part in virtue of $A$ and in part in virtue of something else (partial grounding). When left unspecified, "grounding" here means full grounding.

We also have to distinguish between intrinsic and extrinsic value. Situations have intrinsic value when they have value in themselves, for their own sake, in a non-derivative way (Zimmerman 2015). Pleasure, happiness, friendship, beauty and knowledge, are often cited as states that may ground intrinsic value (for an exhaustive list, see Frankena 1973). Situations have extrinsic value when their value is derivative; for example, when they have value merely in virtue of the fact that they tend to bring about situations that have intrinsic value. When I talk about value without qualification, I mean intrinsic value. Philosophers sometimes also distinguish between various heterogeneous kinds of intrinsic value, for example, between epistemic value, ethical value and aesthetic value (Kriegel in press). I will not presuppose any such distinction here and will simply talk of intrinsic value (as something that may or may not be correctly thus specified), although my attention will be mostly focused on what people usually call "ethical value".

The way I think about it, value can be positive or negative: situations are good when they have positive value, bad when they have negative value. I think val-

3. At the end of this paper, I will say a word about views that reject this presupposition. 
ues are comparable (some situations are better or worse than others) but I will stay neutral on whether or not they are commensurable (so that one situation can be, say, two times better than another one), though I suspect they are. I will also remain neutral on the relation between value and other normative notions such as duties and rights (when I am not, I will be explicit about it).

Finally, judgments about values are normative judgments. In this paper, I will make the (substantive) assumption that normative judgments have a truth-value (i.e., I will assume cognitivism regarding judgments of value). When adopting a new theory implies that we should revise our judgments regarding what has value (or the ordering of values), I will say that this theory has revisionary normative consequences. I will also assume-and this assumption will not be used as a premise in any argument, but is important in order to grasp the general spirit of the paper-that we are prima facie resistant to revisionary normative consequences. Thus, we all have some kind of motivation (which is not the same thing as a justification) to avoid theories which have such consequences, particularly when the revision they imply is radical.

\section{Two Theses Regarding the Link between Phenomenality and Value}

I now turn to the idea that there is a link between phenomenality and value. I will present and discuss two theses regarding the relation between phenomenality and value. Let us start with the weaker of the two - an attractive, widely accepted thesis I call Phenomenal Value.

Phenomenal Value: The instantiation of some standard phenomenal properties grounds (or would ground) intrinsic value.

Phenomenal Value states that there are at least some phenomenal properties such that their instantiation fully grounds (or would fully ground) intrinsic value. It specifies that these properties must be standard. Here, by "standard", I mean that these properties are of a kind that phenomenal realists take to be commonly instantiated. This is necessary in order to make it clear that the thesis would not be made true by some rare and complex value-making phenomenal properties. This thesis is compatible with there being only one value-making property (say, phenomenal pain), as long as it is a standard one.

Phenomenal Value is compatible with the idea that, even if some phenomenal states fully ground some intrinsic value, the total value of the situations in which they take place can sometimes only be partially grounded in these phenomenal states - for example (but not only) if the situations include some non-phe- 
nomenal states (or complex states including non-phenomenal states) also fully grounding value. Importantly, the thesis is formulated in such a way ("grounds (or would ground)") that even an illusionist could accept it. Indeed, even someone who believes that phenomenal properties are never instantiated in reality could also believe that, were some of them to be instantiated, they would ground value.

This thesis, I think, is very widely accepted. In fact, many philosophers who believe that there is a link between phenomenal consciousness and value have gone further than that. They have not only stated that some phenomenal states ground value, but also that only phenomenal states could do it, thus endorsing a stronger thesis, which I call Exclusive Phenomenal Value.

Exclusive Phenomenal Value: The instantiation of some standard phenomenal properties grounds (or would ground) intrinsic value and there is no non-phenomenal property such that its instantiation grounds intrinsic value.

This thesis conjoins Phenomenal Value with the restrictive thesis according to which no instantiation of a non-phenomenal property fully grounds intrinsic value-note that this is merely supposed to hold for instantiated non-phenomenal properties. ${ }^{4} \mathrm{~A}$ very rough approximation of this thesis is that "nothing has value without consciousness". Note that Exclusive Phenomenal Value does not prevent non-phenomenal properties from partially grounding value. It is therefore compatible with the thesis that value does not supervene on the total set of phenomenal states of a situation, and it can accommodate the intuition that, for example, life in an experience machine is not as valuable as life in a "real" world, even if they are phenomenally identical. Note also that, as I think of it, the second clause of Exclusive Phenomenal Value should be read in a way that does not prevent non-phenomenal properties from grounding value if they do it by being identical with phenomenal properties, or by grounding phenomenal properties.

Exclusive Phenomenal Value, compared to Phenomenal Value, is quite a strong thesis - though many philosophers have (at least implicitly) endorsed it. Again, it is formulated in such a way that, in principle, it is not incompatible with illusionism.

4. This thesis might also come in a stronger flavor (Strong Exclusive Phenomenal Value), in which Phenomenal Value is conjoined with the following proposition: "there is no non-phenomenal property such that its instantiation grounds (or would ground) intrinsic value". While Exclusive Phenomenal Value states that there are no actually instantiated non-phenomenal properties which grounds value, Strong Exclusive Phenomenal Value goes further and asserts that, even in the realm of uninstantiated properties, there is no non-phenomenal value-making property. I will set aside here such subtleties and focus merely on Exclusive Phenomenal Value. 


\section{Support for the Link between Phenomenality and Value}

What support is there in favor of these two theses? First, it is worth considering that they are entailed by a great many philosophical views. Numerous views state that nothing in reality grounds intrinsic value but some phenomenal states (or larger states partially composed of phenomenal states), such as, notably, phenomenal pain and phenomenal pleasure. This entails Exclusive Phenomenal Value. This is notably the case of hedonism, 5 according to which nothing is good or bad but felt pleasure and pain - a view which has found prominent defenders in Ancient times (the Cyrenaics and the Epicureans) as well as in the $18^{\text {th }}$ and $19^{\text {th }}$ centuries (La Mettrie, Bentham, Mill) and (with some complexities and qualifications) more recently (Crisp 2006: 103-109; Sprigge 1988: ch. 5; Tännsjö 1998: 84; for an overview, see Moore 2013). Besides, even philosophers who do not embrace hedonism have often claimed that nothing can ground intrinsic value but phenomenal states (Brentano 1952; Kriegel 2018: ch. 9; in press; Seager 2001; van der Deijl 2019). Some other philosophers state that phenomenal consciousness is valuable for itself, which entails at least Phenomenal Value (Glannon 2016; Nagel 1979; for a discussion, see A. Lee 2018). Others assert that most (if not all) of the value of our own lives depends on us being phenomenally conscious (Siewert 1998; 2014), which comes close to endorsing Exclusive Phenomenal Value.

Some philosophers have recently tried to downplay the importance of phenomenal consciousness when it comes to value (Carruthers 1999; 2004; G. Lee 2014; Levy 2014). However, it is worth noting that their goal is often to insist that some non-phenomenal mental states can have value, which entails a rejection of Exclusive Phenomenal Value, but not necessarily of Phenomenal Value. Not all of them explicitly question the idea, for example, that the instantiation of certain phenomenal properties in itself grounds value. This idea seems in fact to be accepted in Levy and Shepherd (in press) and entails Phenomenal Value. G. Lee 2014 comes close to denying Phenomenal Value, but he focuses on the epistemic value of consciousness and does not say much about the other kinds of intrinsic value it might ground.

In conclusion, numerous views endorsed by philosophers throughout history entail Exclusive Phenomenal Value. A number of them reject Exclusive Phe-

5. Of course, this is only true of hedonism if hedonism is conjoined with a phenomenalist understanding of pleasure and pain (according to which pleasure and pain are particular phenomenal feelings) and not, for example, to an attitudinal understanding of these mental states, according to which pleasure and pain are intentional states (Feldman 2002). Traditional hedonistic theories were unclear on whether they take pleasure and pain to be constituted by certain feelings, or by attitudes towards feelings, although I think it is fair to say that most of them were implicitly phenomenalists. This, at least, is very likely to be true for $18^{\text {th }}$ and $19^{\text {th }}$ century hedonists such as Bentham and Mill (as claimed by Moore 2013) but not of Sidgwick (1907), who is arguably one of the first modern thinkers who developed an attitudinal view of pleasure. 
nomenal Value but remain compatible with Phenomenal Value (which they often seem to implicitly accept); and it is difficult to find a view which explicitly denies Phenomenal Value.

Now, what about arguments in favor of such theses? While many such arguments could be devised, I will simply present one for each thesis. Let us start with Phenomenal Value. Given that it is enough to show that there is one standard value-making phenomenal property to prove the thesis, I think the strongest arguments focus on the case of the best candidates to this status: valenced phenomenal properties, and notably phenomenal pain. Let us consider the following situation.

Pure Suffering: Let us imagine that a man named Piotr, a genuinely conscious being endowed with phenomenal states, suffers from a rare disease. Every night, during sleep, he wakes up and, for one hour, feels the most excruciating pain one can imagine. The pain is so intense that it leaves him unable to move or to talk (or to have any observable behavior). For one hour, his life is entirely filled by nothing but the most awful pain ever felt (Consider the worst kind of dental pain multiplied a hundred times over): he undergoes Pure Suffering. He then goes back to sleep. In the morning, he systematically forgets about everything that has happened to him during the night: these nocturnal episodes of pain do not leave any memory, conscious or unconscious, and do not change his psychological dispositions.

I take it to be extremely intuitive that Pure Suffering has negative value. I also take it to be very intuitive that it has negative value in virtue of the pain felt by Piotr (the thought experiment eliminates some-but not all-of the non-phenomenal candidates for the grounding of negative value: trauma, negative memory, aversive behavior, etc.). Therefore, this thought experiment makes it intuitive that phenomenal pain grounds negative value, which entails Phenomenal Value.

It is important to note that, prima facie, even an illusionist can accept this argument for Phenomenal Value. After all, even if consciousness does not exist, we can still conceive of it (at least, that is what I presupposed). Which means that Pure Suffering is conceivable. Once we conceive of this situation, it elicits intuitive judgments of value-and I take it that almost everyone, illusionists included, will intuit (at least at first glance!) that this situation has negative value in virtue of how Piotr feels. ${ }^{6}$ True, an illusionist thinks that Pure Suffering is at least nomo-

6. I suppose that, in order to have the intuition, it is enough for the situation to be conceivableit does not have to be possible. As William Seager (who goes even further) puts it: "Questions of value assignment are independent of the kind of possibility which the thought experiment depends upon or exploits. We can assign, if only hypothetically, value to things that are physically 
logically impossible, but that in itself does not prevent her from recognizing that this situation would be bad if it were actual. Similarly, I can recognize that dragons "are" frightening or that the Garden of Eden "is" a delightful place, even if I think that they are nomologically impossible-as long as I recognize that, if dragons, or the Garden of Eden, were real, they would be frightening/delightful.

Aside from this direct argument, it is important to note that Phenomenal Value arguably plays a central role in justifying some of our deep normative beliefs, themselves crucial in our practices. Consider this: first, we believe that conscious states are often much more normatively important than non-conscious states. This is arguably why we care a lot about conscious pain, say, but not about unconscious pain. For example, we use analgesics in surgery to suppress conscious pain, and we do not care much about potential unconscious, subliminal pain happening somewhere in the brain of the patient during anesthesia. In other words, we endorse the following thesis, which I call Consciousness Contrast: allegedly phenomenal states have an importantly different value from their non-allegedlyphenomenal counterparts. 7

Second, we usually believe that sentient creatures (who have allegedly phenomenal pain or pleasure) have more importance (or more dignity, or more rights) than non-sentient creatures. This is arguably why we care (at least a little bit) about what happens to creatures we judge to be sentient (dogs, cows, pigs, birds, etc.) while we do not care-except for instrumental reasons - about creatures and things we judge to be non-sentient (bacteria, trees, rocks, computers, etc.). Deciding whether or not some creatures are sentient (particularly for "limit cases" such as fish, lobsters, bees, etc.) usually directly affects our opinions on whether or not we should care about them. Generally speaking, we seem to consider that allegedly phenomenal consciousness is crucial for the status of a creature as a genuine moral patient (Levy \& Shepherd in press; Seager 2001; Sebo 2017; Shepherd 2016; Singer 2011). In other words, we endorse the following thesis, which I call Sentience Contrast: creatures that enter allegedly phenomenal pain and pleasure ("sentient creatures") importantly matter more than the crea-

impossible or even metaphysically impossible (perhaps even to things that are logically impossible - I might wish that arithmetic had not "turned out to be" incomplete for example)" (2001: 3 ). I will come back later to the problem of ascribing value to impossible situations.

7. I use the "allegedly phenomenal" locution here because I want to describe this normative thesis (as well as the next one, Sentience Contrast) in a way that remains neutral between illusionism and realism. Nota bene: (I) it is only for the phenomenal realist that allegedly phenomenal pain is the same as phenomenal pain. The illusionists think it is only quasi-phenomenal pain. (2) Non-allegedly-phenomenal pain is not zombie pain nor quasi-phenomenal pain, as it is arguably functionally different from allegedly phenomenal pain. Non-allegedly-phenomenal pain is the form of "unconscious pain" occurring in our world that even phenomenal realists will accept as not being phenomenally conscious - for example, subliminal pain. Some people would argue that such a state does not fully deserve the name "pain" - but nothing substantive here depends on this semantic decision. 
tures that do not ("non-sentient creatures"). ${ }^{8}$ Consciousness Contrast and Sentience Contrast are two very intuitive normative theses, which are part of the normative consensus, and are arguably crucial for many of our practices.

I think the conjunction of Phenomenal Value with phenomenal realism is the thesis that most people would naturally appeal to in order to justify these two theses. The reason why allegedly phenomenal states have a different value from their non-allegedly-phenomenal counterparts is that they are phenomenal, and that phenomenal states (or at least some of them) ground intrinsic value. And it is this extra value had by such states that gives in turn more importance (or dignity, or rights) to the creatures able to enter into such states-sentient creatures.

Now that we have examined the support for Phenomenal Value, as well as its role in justifying some central normative beliefs, let us turn to Exclusive Phenomenal Value. What are the arguments in favor of this thesis? I think that the best arguments appeal to thought experiments featuring worlds devoid of consciousness, which aim to elicit the intuition that such worlds have no value. Of course, there is disagreement about which worlds devoid of consciousness are possible/ conceivable. Some people think that a possible/conceivable world devoid of consciousness is also a world devoid of creatures with our physico-functional properties, or maybe even a world devoid of a certain kind of functional/informational complexity. It seems plausible that, if someone has such an austere conception of a world without consciousness, intuitions that such worlds are valueless are easier to generate. On the other hand, people who believe in the conceivability/ possibility of zombies will have a "richer" conception of what worlds devoid of consciousness can be, which hypothetically makes intuitions that such worlds are valueless harder to get. So, the most challenging (and therefore, the most robust) way to argue in favor of Exclusive Phenomenal Value is through thought experiments involving zombie worlds: worlds identical to ours from the physicofunctional point of view, but devoid of consciousness. ${ }^{9}$ Given that I presupposed earlier that zombies are conceivable, it seems in any case best to take that route. Let us consider the following thought experiment.

Zombie World: Zombie World is exactly identical to our world from the physico-functional point of view. Moreover, Zombie World contains no phenomenal experiences. No one in Zombie World enters phenomenal pain, phenomenal pleasure, or any other phenomenal states: there is nothing it is like to be any of its creatures. Zombies, however, have

8. Again, this normative thesis as such is neutral between illusionism and realism.

9. To the best of my knowledge, the first zombie argument in favor of a link between phenomenality and value has been put forward by Charles Siewert (1998), in order to support the view that phenomenal consciousness is essential to our lives having value. Note that Siewert's thought experiment is a zombification thought experiment, in which a conscious being becomes a zombie. 
behaviors, and an internal physico-functional composition identical to ours: when you hurt them, they shout, they cry, the nociceptive zones in their brains are activated exactly like ours, etc.

Does Zombie World have value? My own intuitions are not particularly clear at this stage-and I suppose that readers will be divided here. Some people will intuit that such a world has exactly the same value as a world populated with genuinely conscious beings. Others will intuit that it does not, but that it still has some value (for example, grounded in some non-phenomenal features that ground value in our own world: informational complexity, cosmic beauty/harmony, the existence of true representations, the existence of functionally conceived desires and attitudes, etc.). However, I suspect that a number of readers would tend to answer that Zombie World has no value; that its existence is entirely indifferent. This intuition is the one needed to support Exclusive Phenomenal Value. Note that an illusionist (who believes that we live in Zombie World) could in principle have any of these intuitions, and that she could therefore end up accepting this argument for Exclusive Phenomenal Value. ${ }^{10}$

\section{The Normative Challenge for Illusionist Views of Consciousness}

That there is a link between phenomenality and value-the one expressed by Phenomenal Value, or the stronger link expressed by Exclusive Phenomenal Valueis, I think, quite an attractive position. As I showed, it is entailed by a great variety of influential philosophical views, it is directly supported by arguments, and it plays (in its weak version, when conjoined with phenomenal realism) an important role in justifying some of our central normative beliefs and practices.

Because this position is attractive, it creates a challenge for illusionists: the normative challenge. Illusionists must decide whether or not they accept that there is such a link between phenomenality and value, and say where they stand regarding these two theses. Depending on their answer, they might be led or not to revisionary normative consequences. If they end up being committed to such consequences, the challenge for them is to explain what these normative consequences exactly are, see if they can be limited in scope, and eventually show how

10. One might note that, by formulating this thought experiment in terms of "zombies", we might tend to presuppose (implicitly) the falsity of illusionism and the truth of phenomenal realism. This could in turn pump our normative intuitions in some particular directions (possibly problematic from the point of view of an illusionist). For more on the difficulties we might face when we try to get rid of our realist intuitions, as well as the effect it might have on our intuitions regarding what has value, see Section 6.3, item iv. 
we can live with them. If they avoid being committed to revisionary normative consequences (which, I will show, probably requires them to reject Phenomenal Value), the challenge for them is to explain why the idea that there is such a link between phenomenality and value seems true even though it is false. Moreover, rejecting Phenomenal Value does not entirely guarantee illusionists against all revisionary normative consequences; they still have to make sure that their view of the non-phenomenal ground of value salvages our intuitive view of what has value. If it does not, then again they have to clarify which exact revisionary normative consequences they accept, and show how we can live with them.

Let us now examine the options an illusionist can take regarding the thesis that there is a link between phenomenality and value. There are three main options: (1) the nihilist option, (2) the moderate option, (3) the conservative option.

The nihilist option. Accept Exclusive Phenomenal Value. If an illusionist accepts Exclusive Phenomenal Value, she is naturally committed to radical revisionary normative consequences. Indeed, she has to say that there are no instantiated properties in the world that ground intrinsic value: therefore, that no situation in the world has intrinsic value. This position is a nihilist one. Nihilism creates all kinds of difficulties (including "pragmatic" ones: if nihilism is true, it means that it is false that we should believe so, which maybe means that we cannot believe it, see Streumer 2013) but one cannot assume that it is false-and I will not here. After all, even if most philosophers judge it to be unattractive, it has been defended independently of issues regarding phenomenal consciousness (Mackie 1977). However, we can also admit that the view that nothing has value is radically revisionary, and that it will not be easy to answer the normative challenge if one takes that option, that is, that it will not be easy to learn to live with it.

The moderate option. Reject Exclusive Phenomenal Value, accept Phenomenal Value. By denying Exclusive Phenomenal Value, the illusionist avoids the commitment to nihilism. At the same time, she might still accept Phenomenal Value - the weaker, more widely accepted, most intuitively supported thesis - which means that she grants that the instantiation of some phenomenal properties (maybe at least phenomenal pain and pleasure?) would ground intrinsic value. In that case, I will show that it is extremely difficult to avoid at least some revisionary normative consequences. The illusionist who chooses the moderate option then has to face two tasks. First, she must explain precisely which revisionary consequences she accepts-ideally, showing that these consequences can be limited. Second, she has to justify her denial of Exclusive Phenomenal Value. 
The conservative option. Reject Phenomenal Value. The illusionist who rejects Phenomenal Value (and, therefore, Exclusive Phenomenal Value) has to reject a very intuitive and almost universally accepted thesis, which is a costly move. One advantage is that she is probably in a better position to avoid revisionary normative consequences. However, even she is not entirely guaranteed against such consequences: she still has to give a view of the non-phenomenal ground of value, which makes it clear that such consequences can be avoided (or at least limited). Moreover, she has to justify her denial of Phenomenal Value - which is no trivial task.

This is the structure of the normative challenge. Illusionists must take one of these three options, and all of them create difficulties. These difficulties are quite obvious in the case of the nihilist option. The normative challenge facing the illusionist who takes this route is not unique to illusionism: it is "simply" the more general problem of nihilism. Given that nihilism has been widely discussed by philosophers for at least a century, I will not explore this option any further here-which does not mean I do not take it to be worth discussing. I will focus on the two other options: the moderate option and the conservative option.

\section{Answering the Normative Challenge: The Moderate Option}

\subsection{The Denial of Exclusive Phenomenal Value}

Start with the moderate option: denying Exclusive Phenomenal Value while accepting Phenomenal Value. The "moderate" illusionist first has to justify her denial of Exclusive Phenomenal Value. Exclusive Phenomenal Value is supposed to be supported by the Zombie World thought experiment, which arguably elicits the intuition that zombie worlds are valueless. This means that the "moderate" illusionist must either: (1) try to elicit different intuitions about such a case, or (2) give a reason not to trust intuitions that zombie worlds are valueless. I think that strategies of the second kind usually also allow one to discard intuitions supporting Phenomenal Value itself, which is why I postpone their presentation to the next section. As for strategies of the first kind, I suspect they have respectable chances of success. Indeed, I do not think that the intuition that zombie worlds are valueless is overwhelming. One can point at various aspects of a zombie world which seem intuitively likely to ground value. For example, zombie worlds are diverse and complex. Arguably, they contain as much "natural" beauty (corresponding to the complex structures of the physical world, or to the harmonious complexities of mathematics) as a world with phenomenal consciousness. Moreover, zombie 
worlds feature complex organized systems. Some of these-zombies-are "cognitive" systems, able to want, to believe, to hope (although in a purely functional, non-phenomenal way). I find it not entirely intuitively implausible that this could ground some value. One strategy to elicit the intuition that zombie worlds have some value (partly inspired by the "Phenumb » thought experiment presented by Peter Carruthers, 1999) ${ }^{11}$ might be to focus our attention on the zombie twin of a human being and try to imagine that something really awful happens to this creature. Let us consider the zombie version of the Pure Suffering thought experiment.

Pure Zombie Suffering: Zombie Piotr, the zombie twin of Piotr (from Pure Suffering), suffers from a rare disease. Every night, during sleep, he wakes up and, for one hour, enters into a state that is physically and functionally indistinguishable from the state of Piotr when Piotr feels the most excruciating pain one can imagine. For this one hour, Zombie Piotr is unable to move or to talk (or to have any observable behavior), in virtue of the functional properties of the state he is in. Even though he does not have any phenomenal experience, all of his functionally conceived mental states-desires, judgments, etc. - are similar to the ones had by Piotr when Piotr suffers: he undergoes Pure Zombie Suffering. Zombie Piotr then goes back to sleep. In the morning, he systematically forgets about everything that has happened to him during the night; these nocturnal episodes of zombie pain do not leave any memory, conscious or unconscious, and do not change his psychological dispositions.

During Pure Zombie Suffering, Zombie Piotr is in zombie pain. True, he does not feel phenomenal pain, but he still keeps judging (functionally) that everything is awful, he keeps having the (functional) ardent desire for his current state to stop, etc. Some of us, I think, would have some kind of empathy for this creature, and ascribe some kind of negative value to his state. Note that one does not need here to intuit that Pure Zombie Suffering is as bad as Pure Suffering: all that is needed is the intuition that Pure Zombie Suffering is not entirely indifferent and that is has some kind of negative value, in order to reject the claim that zombie worlds are valueless. Whether or not such intuitions about the badness of zombie pain are resistant upon reflection, and whether it can lead to satisfying theories regarding the non-phenomenal ground of value, will be examined later.

11. Phenumb is a conscious agent gifted with conscious desires and conscious beliefs, but who does not feel any conscious frustration or sadness whenever his desires are frustrated. Carruthers argues that, when Phenumb is frustrated or sad, he is an appropriate object of sympathy even if his sadness/frustration are not conscious. 


\subsection{The Moderate Option and Its Revisionary Normative Consequences}

Let us assume that the moderate illusionist has successfully rejected Exclusive Phenomenal Value. Given that she accepts Phenomenal Value, where does she stand when it comes to revisionary normative consequences? I think that she will very probably have to accept at least some revisionary normative consequences. Indeed, the illusionist who accepts Phenomenal Value thinks that the instantiation of some standard phenomenal properties would ground intrinsic value. As an illusionist, she also thinks that human beings are intuitively phenomenal realists as they are under the illusion of phenomenality. So, the moderate illusionist accepts that many real situations do not feature the phenomenal properties that they are intuitively thought to feature, and she accepts that these phenomenal properties would ground intrinsic value. At this point, the only way for the illusionist to avoid the conclusion that these real situations do not have as much value as they would have if, as people intuitively think, they had phenomenal properties, would be to say this: in all these situations, the exact same intrinsic value that would be grounded by phenomenal properties is always already grounded by some non-phenomenal properties. But this would require an amazing coincidence, as this would mean that, in the case of the phenomenal version of such situations (the one which realists take to be actual), the same intrinsic value always and systematically would have two distinct full grounds. ${ }^{12}$ Supposing such an amazing coincidence seems exceedingly ad hoc. Therefore, embracing illusionism and Phenomenal Value very probably leads to revisionary normative consequences.

What exactly are these revisionary normative consequences? This depends on the exact view one embraces regarding which phenomenal properties would ground value. If one grants, for example, that phenomenal pain and phenomenal pleasure would ground value (negative or positive), the natural consequence will be that allegedly phenomenal pain and pleasure are simply not as good and bad as what they would be if the realist were right (which does not mean they have no value at all). This arguably extends to the case of other putative valuemaking phenomenal properties.

This can very well appear to be an uncomfortable consequence for illusionists: do they really want to say that their theory implies that pain is not as bad as what we originally thought? The concrete normative consequences are potentially quite dramatic: it could for example imply that (say) torture or factory farming (and other things that we usually judge to be bad at least partly because

12. Another more attractive, less ad hoc option for the illusionist is of course to say that there are not two full grounds of value in all of these situations, but only one full ground-which is not phenomenal. But this option requires one to deny Phenomenal Value, and it will therefore be examined later. 
they involve pain) are not as bad as we thought. ${ }^{13}$ This could in turn have consequences regarding what we should do regarding these things (providing some assumptions about the link between values and duties).

On the other hand, the moderate illusionist can say, for example, that allegedly phenomenal pain (which, for her, is quasi-phenomenal pain - in what immediately follows, I will simply write "pain"), is bad, for reasons that have nothing to do with its (in any case nonexistent) phenomenality (though, barring the amazing coincidence I mentioned earlier, she has to accept that it is not as bad as it would be if the realist were right). However, she then faces two challenges. First, she has to give reasons to think that pain is bad; second, she has to ultimately give a theory of what makes pain bad (the same thing would happen with other states, but here I focus on pain). ${ }^{14}$ This is no trivial task for an illusionist.

First, it is no trivial task for the illusionist to justify the thesis that pain is bad, because the illusionist cannot appeal to the fact that the badness of pain is immediately manifest through introspection - at least not in the same way the realist can. True, the illusionist can justify the badness of pain by the fact that we usually judge that pain is bad, and even that we usually judge immediately (i.e., intuit) that pain is bad when it happens to us or to others. ${ }^{15}$ However, the illusionist cannot say - contrary to some realists - that the nature of pain is entirely and immediately revealed to us. The idea that introspection reveals the entire nature of

13. On a side note: if someone holds the view that nothing grounds value in the world but allegedly phenomenal states, conjoined with Phenomenal Value, and then comes to embrace illusionism, she is certainly committed to the idea that allegedly phenomenal states are not as good/bad as what she thought. However, depending on how she then determines the value of the states she thinks are actual (quasi-phenomenal states), she may simply "rescale" all of the values of real situations, so that the ordering of the value of all situations remains similar to what she believed before embracing illusionism. She would conclude that things are not as good or as bad as what she thought, but that all comparative relations of value (better/worse) still hold exactly as before. Such an option is closed if the subject holds the view that at least one actual thing outside of allegedly phenomenal states grounds value. Thanks to Johannes Martens for pressing this point.

14. I differentiate these two steps because I think they can be separated. For example, let us consider the statement: "Mary's car is yellow". I can justify this statement by appealing, say, to perception or to testimony; I can then give an explanation of what makes this statement true (appealing to the reflectance profile of the surface of Mary's car). These two processes seem quite different, although they can eventually be linked.

15. This seems to be the strategy suggested by Luke Muehlhauser when he states that illusionism regarding consciousness might have no consequences when it comes to the value of pain:

What are the implications of illusionism for my intuitions about moral patienthood? In one sense, there might not be any. After all, my intuitions about (e.g.) the badness of conscious pain and the goodness of conscious pleasure were never dependent on the "reality" of specific features of consciousness that the illusionist thinks are illusory. Rather, my moral intuitions work more like the example I gave earlier: I sprain my ankle while playing soccer, don't notice it for 5 seconds, and then feel a "rush of pain" suddenly "flood" my conscious experience, and I think "Gosh, well, whatever this is, I sure hope nothing like it happens to fish!" And then I reflect on what was happening prior to my conscious experience of the pain, and I think "But if that is all that happens when a fish is physically injured, then I'm not sure I care". (Muehlhauser 2017) 
phenomenal states is one of the tenets of the traditional realist epistemology of phenomenality. The illusionist takes introspection to be illusory, and therefore cannot appeal to such a principle: our pain, which is really quasi-phenomenal pain, is not revealed to us. However, without such epistemology (or something in the vicinity), why should we particularly trust our judgments, or even our immediate judgments (i.e., intuitions), about the badness of pain - or of anything? Human history, after all, is full of widespread normative judgments and intuitions that we now take to be completely false and misguided. Note that, on the other hand, realists who endorse something akin to the traditional epistemology of phenomenal states are often inclined to think that statements of value concerning phenomenal states (for example, concerning the badness of pain or the goodness of pleasure) are uniquely justified compared to other statements of value. Seager, for example, stresses the contrast between our apprehension of the value of phenomenal states and of other states of affairs:

The general problem here is that although it is easy to see why states of consciousness are intrinsically valuable since they have a subjective component that, so to speak, directly reveals their value [ ... ] it is impossible to see why any non-conscious state should have intrinsic value $[\ldots]$ One can, of course, assert that diversity, say, is intrinsically valuable, but unless diversity is tied to some conscious being's appreciation of diversity, which it almost invariably is [ ... ] the assertion seems completely empty and devoid of support. (2001: 4$)^{16}$

Of course, many phenomenal realists (especially the ones who are also materialists) do not endorse such a strong epistemology of phenomenality: does that mean that they, too, are in difficulty when it comes to justifying the badness of pain? It might be, one could answer, that we are just setting the bar too high here: in order to justify our belief that pain is bad, we do not really need to say that this badness is grasped through a process of introspection and that introspection reveals phenomenal states. We simply need to say that badness is grasped through introspection and that introspection is a reliable (though fallible and imperfect) way of forming beliefs about such states. But here one can see that there is a difference between the realist and the illusionist's position. Phenomenal realists with a "weak" epistemology can say that introspection is not revelatory, but constitutes a reliable way of acquiring information about the nature of phenomenal

Muehlhauser actually rejects this interpretation of his position (as this passage simply describes one of his moral intuitions, but not his ultima facie moral judgment), but I nevertheless think that it would constitute an interesting position, attractive at least to some illusionists.

16. For the idea that the badness/goodness of pain/pleasure are uniquely justified, see also (Sinhababu 2012). 
states, so that we would be justified in trusting our introspective verdicts regarding the badness of pain. But the illusionist cannot as easily appeal to this kind of weaker thesis, as she claims that introspection systematically generates incorrect representations about the nature of our internal states. This casts a serious doubt on the reliability of introspective judgments - including the judgments according to which, for example, pain (the pain we really have: quasi-phenomenal pain) is bad.

At this point, I suspect that the best strategy is for illusionists to appeal to other, non-introspective ways to justify the badness of pain. In order to do the job, however, illusionists have to make sure that no hidden appeal to introspection is made. We might want to say, for example, that we know that pain is bad through the testimony of others, but it is likely that others' claims must themselves be justified by introspection. Alternatively, one might want to say that we know that quasi-phenomenal pain is bad a priori, simply by reflecting on it: but it is unclear how reflection on a physical-functional state could deliver such intuition. Moreover, this would arguably imply that, as long as we do not have a correct physical-functional theory of quasi-phenomenal pain, we cannot justify that it is bad, which seems extremely unsatisfying. Finally, one might suggest that we know directly that pain is bad on the basis of empathy: perceiving with empathy that someone is in pain gives us a direct grasp of the badness of their pain. It is notably to this way of knowing the badness of pain that I appealed earlier when I tried to elicit the intuition that Pure Zombie Suffering is bad: we can maybe feel empathy towards Zombie Piotr when he undergoes zombie pain, which makes us know that his pain is bad. It remains to be seen if such a "second-person" epistemology of the value of mental states can be worked out in details (after all, we can be made to feel empathy for many things, including inanimate objects), and if it can really solve the illusionist's difficulty.

Another difficulty is that it is no trivial task for the illusionist to explain what makes pain bad - what grounds its badness. She cannot appeal to its intrinsic phenomenal quality, given that she thinks pain is not phenomenal. Appealing to some kind of rationalistic moral principle (for example, a Kantian principle) will probably give the verdict that some situations in which someone is in pain are bad (for example, situations in which someone is treated as a mere means), but it will not be the case of all of them - it is unclear, for example, why Kantian principles would imply that Pure Zombie Suffering is bad. Looking at quasi-phenomenal pain from a purely physiological point of view (as a brain state), on the other hand, is unlikely to give us a satisfying account of its badness: nothing in the mere description of a brain state seems fit to explain the presence of value. The best option here for the illusionist would probably be to draw inspiration from desire-satisfaction views of well-being (Brandt 1979; Heathwood 2006) or from attitudinal theories of valenced states (Feldman 2002), and to say that pain is bad 
(even if it is not phenomenal) because it constitutively includes the frustration of a desire, or the having of a certain negative attitude of dislike. After all, when I am in pain, there is something awful which is that I want it to stop (and that my desire is frustrated); alternatively, one could insist on the fact that what is bad is that I dislike my pain. This frustration or this dislike are what makes pain a harm, which in turn grounds its negative value. This might be the most promising lead to an account of what makes pain bad.

I said earlier that the conjunction of Phenomenal Value with phenomenal realism was the natural justification of two central normative theses: Consciousness Contrast and Sentience Contrast. Can the illusionist who takes the moderate option conserve these two theses?

The illusionist who accepts Phenomenal Value, is forced (barring the amazing coincidence) to admit that allegedly phenomenal states do not ground as much value as they would have if the realist were right, which means that the contrast between allegedly phenomenal states and non-allegedly-phenomenal states cannot be as stark as if the realist were right. That such contrast has to be weakened is already an important revisionary normative consequence. If the contrast of value between the states is what justifies the contrast of importance (or dignity, or rights) between the creatures, this means Sentience Contrast also has to be weakened.

I said "weakened", because illusionists can still say that there is some kind of difference in value between allegedly phenomenal and non-allegedly-phenomenal states (which can lead to a special status for sentient creatures). But again, the illusionist will have to first justify that such a difference holds - and, again, this will be difficult, as illusionists cannot appeal to the same kind of epistemology of phenomenality as the realist. Second, the illusionist has to explain what grounds such difference in value. But this might be particularly tricky: indeed, if the illusionist has previously accounted for the badness of pain, say, in terms of its inclusion of a frustration of a desire (or of a negative attitude of dislike), it will not be easy to explain why there is a stark contrast in value between quasi-phenomenal pain and non quasi-phenomenal pain. After all, are not both frustrations of desires of some kind (or dislikes of some kind)? Peter Carruthers (2004), who defends a similar view of what grounds the badness of pain (although he is not an illusionist), seems to concur with this idea. He thus emphasizes that the harm (that I interpret here as grounding some negative value) constituted by non-conscious pain (i.e., non-allegedly-phenomenally conscious pain) is not as radically distinct from the harm constituted by conscious pain (i.e., allegedly phenomenally conscious pain) as what is usually thought. But this endangers the justification of Consciousness Contrast (and, hence, of Sentience Contrast).

One might emphasize the difference between the value of the two kinds of states by appealing to differences in the frustrated desires (or differences in the 
attitudes of dislike). Maybe it is worse to frustrate a quasi-phenomenal desire than a non quasi-phenomenal desire; or to dislike something in a quasi-phenomenal way than in a non quasi-phenomenal way. However, this in turn seems to stand in need of justification - why should we believe that it is worse? - and an explanation-what makes it worse exactly? At any rate, such a view would need to be elaborated in detail.

To close this section: the illusionist who takes the moderate option must very probably face some revisionary normative consequences. Some mental states do not have the value they would have if the realist were right, which also leads to a weakening of the contrast between states (allegedly phenomenal versus non-allegedly-phenomenal) and creatures (sentient versus non-sentient). Moreover, if the illusionist wants to limit these normative consequences - and maintain, say, that some valenced quasi-phenomenal states ground value, and that Consciousness Contrast and Sentience Contrast still hold in a weakened version - she has to give a justification for such theses, and she has to explain what makes them true. As I tried to show, this is no trivial task.

\section{Answering the Normative Challenge: The Conservative Option}

\subsection{The Conservative Option and Its Revisionary Normative Consequences}

Let us now consider the conservative option. Illusionists who take this route reject Phenomenal Value. That seems to put them in a better position to avoid revisionary normative consequences. Indeed, if they reject Phenomenal Value, they deny that the instantiation of phenomenal properties would ground value. Hence, there seems to be no particular reason to think that embracing illusionism should change our view regarding what has value.

However, two things must be noted. First, rejecting Phenomenal Value does not guarantee against all the normative revisionary consequences of illusionism (even if it helps). After all, it might be that no phenomenal states would fully ground value (i.e., Phenomenal Value is false) but that some phenomenal states would partially ground value if they were the case, in such a way that illusionism would have different consequences than realism regarding what currently has value. ${ }^{17}$ Second, it could be that the illusionist who embraces the conservative option is right to reject Phenomenal Value,

17. Here is an example (rather innocuous): if phenomenal states were the case (as the realist think they are), beliefs (that most people have) that we enter into such phenomenal states would be true, which in turn would arguably ground some kind of (epistemic) value. The "same" beliefs do not ground the same value if the illusionist is right. So, that would be at least one (rather modest) 
but that the intuitive default position of most people is to embrace both Phenomenal Value and phenomenal realism, and to thus ascribe a certain value to some allegedly phenomenal states in virtue of them really having a certain phenomenal feel. By rejecting Phenomenal Value, the illusionist can then maybe deny that allegedly phenomenal states would have a different value if they were phenomenal (illusionism does not have revisionary normative consequences compared to realism, assuming that Phenomenal Value is false). However, she cannot guarantee that allegedly phenomenal states have the value that most people intuitively ascribe them-she cannot guarantee that illusionism conjoined with the rejection of Phenomenal Value does not have revisionary normative consequences compared to the intuitive default position-realism conjoined with Phenomenal Value. So, her overall position might still be revisionary compared to the intuitive starting point.

If the illusionist wants to make sure that major revisionary normative consequences are avoided-for example, if she wants to make sure pain and pleasure are as bad as intuitively thought, or if she wants to justify Consciousness Contrast and Sentience Contrast in its strong version, she has to provide two things. Like the illusionist who takes the moderate option, she first has to provide a justification for the theses that (for example) pain is bad and pleasure is good (and that allegedly phenomenal pain/pleasure are especially bad/good when compared to non-allegedly-phenomenal pain/pleasure). She also has to provide an explanation of why these theses hold. However, for the very reasons presented in the previous section, illusionists might encounter difficulties here. The justificatory part is made tricky because illusionists reject the realist epistemology of phenomenality. The explanatory part may feature some tension between an account of the value of valenced quasi-phenomenal states in terms of desire satisfaction/ frustration or in terms of attitudes (like/dislike) on the one hand, and an account of what makes Consciousness Contrast and Sentience Contrast true on the other hand. So, rejecting Phenomenal Value puts illusionists in a better position to avoid revisionary normative consequences, but they still face some serious challenges if they want to do so.

Moreover, rejecting Phenomenal Value presents a difficulty of its own. Indeed, Phenomenal Value is an attractive and intuitively well-supported thesisarguably, much more than Exclusive Phenomenal Value. That means that justifying the rejection of such a thesis is no trivial matter. The illusionist who chooses the conservative option has two possibilities: she can (1) try to change our intuitions regarding Phenomenal Value, or she can (2) admit that Phenomenal Value is intuitively supported, but then discard this intuition, by giving reasons not to trust it. I will first explore the first strategy, and then turn to the second one.

revisionary normative consequence that illusionism could have even if Phenomenal Value is false (as it does not presuppose that phenomenal states fully ground value). 


\subsection{Changing Our Intuitions Regarding Phenomenal Value}

Start with the first strategy: how could illusionists make the intuition that supports Phenomenal Value disappear? Let us consider the thought experiment I called Pure Suffering. We have a strong intuition that this situation is bad. This intuition is unlikely to change (and changing it would anyway not help the illusionist with dealing with revisionary consequences). But we also have a strong intuition that this situation is bad in virtue of what Piotr feels - that is, in virtue of his phenomenal states. This is what gives support to Phenomenal Value. Maybe illusionists can pump our intuition in another direction?

One way to do so would be to claim that, if we think harder, we will understand that what we intuitively find bad in Piotr's pain is not something grounded in phenomenality. For example, drawing inspiration from the already mentioned attitudinal theories of valenced states (or from desire-satisfaction theories of well-being), illusionists could claim that what is intuitively bad about Piotr's pain is not the way it feels (the pain quale). In fact, it is (1) the fact that Piotr dislikes the way pain feels, and/or (2) the fact that he desires this feeling to stop (and that this desire is frustrated). After all, the same painful "feeling" would maybe not be bad if Piotr liked it (or if he wanted it to go on): if a masochist enjoys her pain and wants it to go on, it seems doubtful that her pain is really bad. But if it is not the phenomenal aspect of Piotr's pain that makes it intuitively bad, but his dislike of it/his desire for it to stop, then intuitive support for Phenomenal Value seems to vanish.

Can the illusionist successfully pump our intuition in that direction? Maybe. But here we need to approach things with precautions. Indeed, notice that the idea according to which what is bad in pain is not the pain quale, but rather the fact that pain is disliked, or that it generates a frustrated desire, only allows us to counter Phenomenal Value if we use a concept of dislike and a concept of desire that make it clear that they do not have to be phenomenal (or grounded in the phenomenal). But I precisely suspect that, when we find intuitive the idea that the badness of pain does not come from its quale but from us disliking it/wanting it to stop, we implicitly use a phenomenal concept of dislike/desire.

One way to make this problem clear is this: if the phenomenality of pain (including the phenomenality of dislikes, and the phenomenality of frustrated desires) is not intuitively what makes it bad, then Pure Zombie Suffering should be intuitively as bad as Pure Suffering. Indeed, Zombie Piotr has the same attitude of dislike (non-phenomenally conceived) towards his pain, and the same (nonphenomenal) desire for it to stop, as conscious Piotr. But I find it personally very hard to have such an intuition: I can intuit some negative value in Zombie Pure Suffering, but intuitively it also seems that there is an important difference with Pure Suffering, which makes this situation simply less bad. 
There is another other way to make it clear that the intuitive plausibility of such accounts of the badness of pain relies on an implicit acceptance of a phenomenal conception of dislikes and frustrated desires. It appeals to imaginary cases of hedonic inversions (Kahane 2009: 334; cited in Levy \& Shepherd in press). Let us imagine that Piotr's friend, Natasha (a conscious being), suffers from a neighboring condition, except that instead of feeling pain for one hour every night, she feels bliss. Let us call this situation Pure Bliss. Now, let us suppose that there is a third character, "Inverted Qualia" Andrei, who, each night, enters for one hour in a state that is phenomenally exactly identical to Pure Bliss (Natasha's state), but functionally and physically exactly identical to Pure Suffering and Pure Zombie Suffering (Piotr and Zombie Piotr's states). Let us call his situation Inverted BlissSuffering. I take it to be extremely intuitive that such situation is not as bad as Pure Suffering: how could it be, given that "Inverted Qualia" Andrei feels nothing but phenomenal bliss, instead of phenomenal pain? But if what makes intuitively pain bad is the fact that we dislike it, or the fact that we desire it to stop, and if such dislike and desire are intuitively not phenomenal (nor grounded in the phenomenal), then we should intuitively admit that Inverted Bliss-Suffering (and, of course, Pure Zombie Suffering) is exactly as bad as Pure Suffering. ${ }^{18}$ I find it intuitively unacceptable-which is not to say here that I claim that they really differ in value.

So, I think that the illusionist will have trouble making our intuitive support for Phenomenal Value vanish. But can she discard this intuition-accept that this thesis seems true, but give reasons not to trust this seeming?

\subsection{Discarding Our Intuitions for Phenomenal Value}

For any intuition, however strong, one can always claim that the proposition supported by the intuition is false. However, given that intuitions-particularly intuitions which do not disappear on reflection-are usually seen as providing support in favor of what is intuited, denying the truth of an intuited claim leaves us in a difficult situation if we are not also able to provide a reason not to trust

18. I presupposed earlier that zombies are conceivable, which notably implies that there is no a priori derivation from physical truths to phenomenal truths. The conceivability of Inverted Bliss-Suffering actually requires more than that, as it also requires that there is no a priori derivation from phenomenal truths to physical truths. So one could technically accept the conceivability of zombies, but not of such inverted qualia. However, it seems to me that philosophers who usually accept that zombies are conceivable should also naturally accept the conceivability of inverted qualia. Moreover, claiming that there is an a priori derivation from phenomenal truths to even simply some physical truths would have all kinds of strange consequences: it would make phenomenal idealism (the view that nothing exists but phenomenal experience), contradictory, and a priori false. That would also make skepticism about the physical world contradictory and a priori false. However, such views do not seem contradictory nor a priori false. 
this particular intuition. Here are a few routes that the illusionist willing to discard the intuition supporting Phenomenal Value might take:

i. Global skepticism regarding intuitions of values. One way to go would be simply to refuse to give weight to any of our intuitions concerning value-including the intuition supporting Phenomenal Value. Some philosophers might find this stance attractive-maybe, for example, error theorists about value (Mackie 1977). It could be justified on the basis of a debunking argument: because of the way our intuitions about values have been acquired (e.g., through a process of natural selection which is not sensitive to value), we should not trust them (Joyce 2006; Street 2006). However, this move is likely to have even more revisionary normative consequences than most other options available to the illusionist (in the most radical case, it leads to nihilism). For that reason, I do not consider it a particularly attractive option in this context.

ii. Skepticism regarding intuitions of values about non-phenomenal states. Another strategy would be to discard some of our intuitions supporting Phenomenal Value - notably our intuition that Pure Suffering and Pure Zombie Suffering have a different value-by claiming that our intuitions regarding the value of some large class of states, such as non-phenomenal states in general, are generally not to be trusted. This strategy is suggested (in a different debate) by Peter Carruthers (1999), who claims that we are bad at properly evaluating non-phenomenal mental states, because we cannot imagine them in the right way, which makes us conclude that they must have no significance at all. I find that a strategy directly inspired by Carruthers's view is probably unsatisfying, in that I think that one can very well intuitively ascribe some negative value to non-phenomenal pain, while also intuiting that there is an important contrast between its value and the value of phenomenal pain-phenomenal pain seeming considerably worse than nonphenomenal pain. But if Carruthers were right, such intuition should not occur, as the cause of our misjudging that there is a stark difference in value between phenomenal pain and non-phenomenal pain would be our incapacity to intuit the negative value of non-phenomenal pain. There might be other, more subtle ways to justify skepticism regarding intuitions of values about non-phenomenal states. However, in order to be satisfying, they generally cannot state that we wrongly only intuit a difference in value between phenomenal states and non-phenomenal states merely because we wrongly intuit that non-phenomenal states have no value.

iii. Skepticism regarding intuitions of values about phenomenal states. On the other hand, one can defend a form of skepticism about our intuition of values regarding phenomenal states: our mistake would not be that we wrongly underestimate the negative value of Pure Zombie Suffering, but maybe that we overestimate the negative value of Pure Suffering. Of course, such skepticism has to be justified independently, on pain of being ad hoc. One first way to go would be to 
say that intuitions concerning the value of Pure Suffering (for example) are justified by introspection, but that illusionism takes phenomenal introspection to be systematically misleading, so that we should not trust the intuitions it delivers. One problem with this strategy is that it is in fact unlikely that we grasp the badness of Pure Suffering via introspection properly speaking. After all, none of us (hopefully) has ever lived Pure Suffering, which means that we do not introspect it! We conceive of it, and we grasp its badness through concept application, through something more akin to an a priori process (different from introspection, which seems to be an a posteriori process). This a priori process allows us to intuit what would be the value of this situation if it were the case, and even if it is never the case (the same way in which I can grasp the frightfulness of dragons, or the delightfulness of Eden). One might insist that this seemingly a priori process is ultimately justified by what we have learnt a posteriori about the badness of our own "normal" pain (that we have introspected!). The problem, however, is that it is unclear that it is really how we learn even about the badness of our own pain: it is doubtful that we introspect that we are in pain in the one hand, and that we are in a bad state in the other hand. Otherwise, conceiving of an intrinsically good pain (or a bad pleasure) would be easy, as we would have two different introspective representations (one for pain, one for badness) whose link is entirely $a$ posteriori and contingent. However, conceiving of an intrinsically bad pain/good pleasure does not seem that easy. So, it seems more plausible that we introspect that we are in pain, where pain is essentially characterized as a state with a certain valence, grounding a certain value. ${ }^{19}$ But, for that reason, casting doubt on the reliability of introspection is not enough to reject the badness of introspected pain (that is, it is not enough to deny that, if such state was real, it would be bad). In the same way, learning that my perception of a dragon is hallucinatory does not undermine the claim that, if the dragon that I hallucinate were real, it would be frightful, big and scaly, given that my (hallucinatory) perception characterizes the dragon as such.

Another way to justify skepticism about the value of phenomenal states is to claim that phenomenal consciousness is impossible - and then discard intuitions of values regarding impossible cases. I supposed earlier that we have trustworthy intuitions of values about all conceivable cases. But this may seem far-fetched, and one could wonder why we should give any kind of weight to our intuitions regarding the value of impossible (though conceivable) situations. Indeed, it is doubtful that we should take seriously theses that state that an impossible situation has a certain value. For example, we could say that "impossible worlds" really are just a way of talking, so that statements about impossible worlds do

19. For reasons of space, I cannot discuss it in details, but I want to point out that this view is not endangered by the existence of medical conditions such as pain asymbolia, as here I use "pain" to refer to pain as normal subjects introspect it. 
not have a truth-value (or maybe they are all trivially true, or false). We can then discard our intuitions about impossible situations having value, because the proposition intuited does not have a (non-trivial) truth-value. If the illusionist combines this idea with the claim that phenomenal consciousness is not only inexistent, but also impossible, she can conclude that we should discard all of our intuitions regarding the value of phenomenal states (including our intuitions supporting Phenomenal Value).

Illusionists willing to take that route still have to fulfill one task: they have to give reasons to think that phenomenal consciousness is impossible. But phenomenal consciousness seems both possible and actual - in fact, almost everyone in history believed it to be actual. Giving arguments for its metaphysical impossibility will be no trivial task and will constitute a genuine theoretical cost. ${ }^{20}$

iv. Skepticism about our value intuitions given our realist intuitions. One other strategy relies on the following idea. According to illusionists, we are all instinctive phenomenal realists, as we are all under the illusion of phenomenality. One can claim that this illusion is so strong that most people (even convinced illusionists), in most contexts, cannot help but systematically fall back into the illusion of phenomenality and believe, deep down, that phenomenality is real. This "gut" belief would then pervade our thought experiments and make us (falsely) believe that Pure Zombie Suffering simply is not what we would undergo if we were in pain (although it really is), but that it lacks a crucial ingredient. Consequently, we (wrongly) intuit that Pure Zombie Suffering is not as bad as Pure Suffering. However, if we could entirely and instinctively believe illusionism, we would lose this intuition. In other words: we know that our pain (the one we really have, which is quasi-phenomenal) is bad, and at the same time we cannot help but believing (falsely) that our pain is phenomenal. We end up forming the belief that the (real) badness is grounded in its (illusory) phenomenality, which makes us believe falsely that Phenomenal Value must be true, and that without phenomenality, pain (for example) is not as bad as with phenomenality; but such belief would disappear if we became intuitive illusionists.

This strategy presents some advantages, but it also has drawbacks. It notably has the consequence that, at the times at which one fully accepts illusionism, the intuition supporting Phenomenal Value should disappear. So, it discards the intuition in favor of Phenomenal Value in a way that also presupposes that it should disappear under the right conditions (it mixes the "changing the intuition" and

20. To the best of my knowledge, the only views which have been developed and which entail the impossibility of consciousness also claim that the very concept of consciousness is incoherent (Dennett 1988; Rey 1995; 1997). That does not fit well with what I presupposed in this paper (i.e., the conceivability of consciousness). I know of no attempt to develop the view that consciousness is conceivable, but metaphysically impossible (which would require to deny modal rationalism: the thesis that what is conceivable is possible). 
the "discarding the intuition" strategies). But that this intuition disappears when we are most convinced of the truth of illusionism is far from obvious - at least to me. One could then claim that there is a sense in which no one ever comes to fully embrace illusionism, because the illusion of phenomenality is too strong, but that would create some difficulty for illusionists - what does it even mean to be an illusionist if you cannot believe illusionism? Illusionists probably could solve this difficulty (for example, by distinguishing different ways in which one can believe a theory), but the resulting view might start to look ad hoc or untestable to some. In my mind, however, this last strategy probably remains the most attractive one for an illusionist who wants to deny Phenomenal Value.

\section{Concluding Remarks}

There is an intuitive link between phenomenality and value. However, according to illusionists, phenomenality does not exist. This creates the normative challenge for illusionist views of consciousness. I think that illusionists should ultimately face up to this challenge. If we take illusionism to be true-or even merely to be one of the serious contenders amongst theories of consciousness - then we have to understand what it implies in the normative domain. If we embrace illusionism, should we revise our judgments concerning what is good and bad, what is better and worse? This, I think, is to a great extent an open (and fascinating) question; but it is a question which, as I tried to show, is not easy to answer, as any stance towards the normative challenge encounters problems.

I have defended illusionism regarding consciousness elsewhere (Kammerer 2016; 2019), and I still think that this is probably the true view of consciousness. One could then wonder which kind of stance towards the normative challenge I recommend. My goal here was not to defend a particular position towards the normative challenge (which would require more arguments), but rather to map the options. However, given what precedes, here is where my preference lies. My favorite option is the "moderate option", as I find it hard to justify the rejection of Phenomenal Value in a satisfying way. Indeed, all the routes I examined for doing so raise serious issues (even though I see a bit more hope in the one I called "Skepticism about our value intuitions given our realist intuitions"). I therefore think we should probably accept some revisionary normative consequences (admit that pain and pleasure are not as bad as thought, and weaken Consciousness Contrast and Sentience Contrast), while also providing views that justify and explain the value of valenced quasi-phenomenal states. The explanatory part will probably have to focus on the attitudes and desires that usually accompany or partly constitute valenced quasi-phenomenal states. As for the justificatory part, I think I am attracted by a second-person epistemology of the value of mental 
states (where empathy plays a crucial role), but I am not sure it can be worked out satisfactorily in the end. In fact, I suspect the justificatory part is going to correspond to the hardest part of the normative challenge for illusionism.

More generally, I am a bit suspicious of views that would manage to avoid revisionary consequences altogether. Revisionary normative consequences may often appear undesirable; but it would be very strange, after all, that a radical revision of our conception of what reality (in general) and the mind (in particular) are-and illusionism really is such a revision-should leave our conception of the value of the states of affairs (in general) and of states of mind (in particular) completely untouched.

Now, in conclusion, let us admit for one second that the best illusionist answer (or maybe all acceptable illusionist answers) to the normative challenge has deeply revisionary normative consequences (nihilism being one of the most striking examples of such deeply revisionary consequences). It would give us a motivation to reject illusionism, as we are usually resistant to normative revisions. However, will this also give us a justification to reject illusionism? In other words, does the normative challenge have epistemic upshots? This will depend on whether or not we have good justifications for our antecedent normative judgments. And here things may quickly become tricky, as illusionism itself might not only lead to contradict these antecedent normative judgments, but might also undercut their justification (for example if these antecedent normative judgments were supposed to be justified by introspection, the status of which, as a reliable justificatory process, is threatened by illusionism).

For the sake of the argument, let us now take our antecedent normative judgments to be independently justified. In this case, the normative challenge would potentially provide the basis of an argument against illusionism. ${ }^{21}$ How should the philosopher who has illusionist inclinations react?

One way to go would be to choose weak illusionism over strong illusionism (which I simply called "illusionism" in this paper). Weak illusionists claim that phenomenal consciousness exists, but does not have many of the problematic properties it is usually thought to have-it merely seems to have these properties. Weak illusionism does not deny the existence of phenomenality, which might seem to help in escaping revisionary normative consequences. However, I think that weak illusionism is at heart an unstable position: that it is either a merely verbal variation on strong illusionism, or that it is in fact incoherent, in the sense that it is implicitly committed to the existence of full-blown phenomenality (endowed with the kind of problematic properties that the weak illusionist explicitly denies). ${ }^{22}$ Another difficulty for weak illusionists in the context of the norma-

21. For an argument against reductive materialism in that spirit, see Cutter (2017).

22. In Keith Frankish's (2012) terms there is no "diet qualia" between "zero qualia" and fullblown qualia: there is no coherent conception of phenomenality which amounts to more than quasi- 
tive challenge stems from the fact that they believe we are the victims of illusions regarding phenomenality: phenomenal states seem to have essential properties they do not really have. But once you admit that our grasp of phenomenality is systematically mistaken in important respects, it becomes difficult to support the idea that the capacity of phenomenal states to ground some form of value is not itself amongst these illusory properties. In that sense, weak illusionists too might have to face revisionary normative consequences. One could also retreat to reductive materialism, which is a variety of phenomenal realism (but still seems closer in spirit to illusionism than, say, dualism or neutral monism). However, I take it that the most plausible versions of reductive materialism will be forms of weak illusionism, which means that they also face the difficulties just described.

Therefore, to the question "Can the normative challenge be used to argue against illusionism?" the answer is "Yes". However, building such an argument will not be easy. Substantive suppositions are needed. Moreover, I doubt such an argument would comparatively give support to neighboring views, such as weak illusionism or reductive materialism: an argument against illusionism based on the normative challenge will probably be an argument against materialism in general (or at least against the most plausible forms of materialism).

\section{Acknowledgments}

I want to thank Romain Bourdoncle, David Chalmers, Keith Frankish, Thibaut Giraud, Uriah Kriegel, Andrew Lee, Tricia Magalotti, Johannes Martens, Luke Muehlhauser, Sonia Paz-Higgins, Andrea Peacocke, Henry Shevlin, Carl Shulman, Jonathan Simon, Cecily Whiteley for their helpful remarks and comments, as well as audiences at the Institut Jean Nicod, at the Université Catholique de Louvain and at New York University. I also want to thank the two anonymous referees for their useful remarks, as well as Robert Mason for his corrections.

\section{References}

Aydede, Murat and Güven Güzeldere (2005). Cognitive Architecture, Concepts, and Introspection: An Information-Theoretic Solution to the Problem of Phenomenal Consciousness. Noûs, 39(2), 197-255. https://doi.org/10.1111/j.0029-4624.2005.00500.x

Balog, Katalin (2012). Acquaintance and the Mind-Body Problem. In C. Hill and S. Gozzano (Eds.), New Perspectives on Type Identity: The Mental and the Physical (16-42). Cambridge University Press.

phenomenality but is still distinct from "classic" phenomenality. The weak illusionist is either a strong illusionist or a phenomenal realist in disguise. 
Block, Ned (1995). On a Confusion about a Function of Consciousness. Brain and Behavioral Sciences, 18, 227-247. https://doi.org/10.1017/S0140525X00038188

Brandt, Richard (1979). A Theory of the Good and the Right. Clarendon Press.

Brentano, Franz (1952). Grundlegung und Aufbau der Ethik, Nach den Vorlesungen über Praktische Philosophie. Meiner.

Carruthers, Peter (1999). Sympathy and Subjectivity. Australasian Journal of Philosophy, 77(4), 465-482. https://doi.org/10.1080/00048409912349231

Carruthers, Peter (2004). Suffering without Subjectivity. Philosophical Studies, 121(2), 99125. https://doi.org/10.1007/s11098-004-3635-5

Chalmers, David (1996). The Conscious Mind: In Search of a Fundamental Theory. Oxford University Press.

Chalmers, D. (2002). Consciousness and Its Place in Nature. In David Chalmers (Ed.), Philosophy of Mind: Classical and Contemporary Readings (247-272). Oxford University Press.

Chalmers, David (2007). Phenomenal Concepts and the Explanatory Gap. In T. Alter and S. Walter (Eds.), Phenomenal Concepts and Phenomenal Knowledge: New Essays on Consciousness and Physicalism (167-194). Oxford University Press. https://doi.org/10.1093/ acprof:oso/9780195171655.003.0009

Chalmers, David (2018). The Meta-Problem of Consciousness. Journal of Consciousness Studies, 25(9-10), 6-61.

Crisp, Roger (2006). Reasons and the Good. Oxford University Press. https://doi.org/10.1093/ acprof:oso/9780199290338.001.0001

Cutter, Brian (2017). The Metaphysical Implications of the Moral Significance of Consciousness. Philosophical Perspectives, 31(1), 103-130. https://doi.org/10.1111/ phpe.12092

Demircioğlu, Erhan (2013). Physicalism and Phenomenal Concepts. Philosophical Studies, 165(1), 257-277. https://doi.org/10.1007/s11098-012-9959-7

Dennett, Daniel (1988). Quining Qualia. In A. Marcel and E. Bisiach (Eds.), Consciousness in Contemporary Science (42-77). Oxford University Press. https://doi.org/10.1093/acp rof:oso/9780198522379.003.0003

Dennett, Daniel (1991). Consciousness Explained. Penguin.

Dennett, Daniel (2016). Illusionism as the Obvious Default Theory of Consciousness. Journal of Consciousness Studies, 23(11-12), 65-72.

Dennett, Daniel (2017). From Bacteria to Bach and Back. Norton \& Company.

Diaz-León, Esa (2014). Do a Posteriori Physicalists Get Our Phenomenal Concepts Wrong? Ratio, 27(1), 1-16.

Elpidorou, Andreas (2013). Having It Both Ways: Consciousness, Unique Not Otherworldly. Philosophia, 41(4), 1181-1203. https://doi.org/10.1007/s11406-013-9455-0

Elpidorou, Andreas (2016). A Posteriori Physicalism and Introspection. Pacific Philosophical Quarterly, 97(4), 474-50o. https://doi.org/10.1111/papq.12068

Feldman, Fred (2002). The Good Life: A Defense of Attitudinal Hedonism. Philosophy and Phenomenological Research, 65(3), 604-627. https://doi.org/10.1111/j.1933-1592.2002. tb00223.x

Feyerabend, Paul (1963). Mental Events and the Brain. Journal of Philosophy, 60(11), 295296. https://doi.org/10.2307/2023030

Fine, Kit (2012). Guide to Ground. In Fabrice Correia and Benjamin Schnieder (Eds.), Metaphysical Grounding (37-80). Cambridge University Press. https://doi.org/10.1017/ CBO9781139149136.002 
Frankena, William (1973). Ethics (2nd ed). Prentice Hall.

Frankish, Keith (2012). Quining Diet qualia. Consciousness and Cognition, 21(2), 667-676. https://doi.org/10.1016/j.concog.2011.04.001

Frankish, Keith (2016). Illusionism as a Theory of Consciousness. Journal of Consciousness Studies, 23(11-12), 11-39.

Glannon, Walter (2016). The Value and Disvalue of Consciousness. Cambridge Quarterly of Healthcare Ethics, 25(4), 600-612. https://doi.org/10.1017/S0963180116000335

Goff, Philip(2011).A PosterioriPhysicalists GetOurPhenomenalConceptsWrong. Australasian Journal of Philosophy, 89(2), 191-209. https://doi.org/10.1080/00048401003649617

Graziano, Michael (2013). Consciousness and the Social Brain. Oxford University Press.

Heathwood, Chris (2006). Desire Satisfactionism and Hedonism. Philosophical Studies, 128, 539-563. https://doi.org/10.1007/s11098-004-7817-y

Irvine, Liz and Mark Sprevak (in press). Eliminativism about Consciousness. In Uriah Kriegel (Ed.), Oxford Handbook of the Philosophy of Consciousness. Oxford University Press.

Jackson, Frank (1982). Epiphenomenal Qualia. Philosophical Quarterly, 32(127), 127-136. https://doi.org/10.2307/2960077

Joyce, Richard (2006). The Evolution of Morality. MIT Press. https://doi.org/10.7551/mitpress/2880.001.0001

Kahane, Guy (2009). Pain, Dislike and Experience. Utilitas, 21(3), 327-336. https://doi. org/10.1017/S0953820809990070

Kammerer, François (2016). The Hardest Aspect of the Illusion Problem - and How to Solve It. Journal of Consciousness Studies, 23(11-12), 123-139.

Kammerer, François (2019). The Illusion of Conscious Experience. Synthese. https://doi. org/10.1007/s11229-018-02071-y

Kriegel, Uriah (2009). Subjective Consciousness: A Self-Representational Theory. Oxford University Press. https://doi.org/10.1093/acprof:oso/9780199570355.001.0001

Kriegel, Uriah (2018). Brentano's Philosophical System. Oxford University Press. https:// doi.org/10.1093/oso/9780198791485.001.0001

Kriegel, Uriah (in press). The Value of Consciousness: A Propaedeutic. Analysis.

Lee, Andrew (2018). Is Consciousness Intrinsically Valuable? Philosophical Studies, 175(1), $1-17$.

Lee, Geoffrey (2014). Materialism and the Epistemic Significance of Consciousness. In Uriah Kriegel (Ed.), Current Controversies in Philosophy of Mind (222-245). Routledge. https://doi.org/10.4324/9780203116623-10

Levine, Joseph (2001). Purple Haze: The Puzzle of Consciousness. Oxford University Press.

Levine, Joseph (2007). Phenomenal Concepts and the Materialist Constraint. In Torin Alter and Sven Walter (Eds.), Phenomenal Concepts and Phenomenal Knowledge: New Essays on Consciousness and Physicalism (145-166). Oxford University Press.

Levy, Neil (2014). The Value of Consciousness. Journal of Consciousness Studies, 21(1-2), 127-138.

Levy, Neil and Joshua Shepherd (in press). Consciousness and Morality. In Uriah Kriegel (Ed.), The Oxford Handbook of the Philosophy of Consciousness. Oxford University Press.

Loar, Brian (1997). Phenomenal States (Revised Version). In Ned Block, Owen Flanagan, and Güven Güzeldere (Eds.), The Nature of Consciousness (597-616). MIT Press.

Mackie, John L. (1977). Ethics: Inventing Right and Wrong. Penguin.

Moore, Andrew (2013). Hedonism. In Edward N. Zalta (Ed.), The Stanford Encyclopedia 
of Philosophy (Winter 2013 ed.). Retrieved from https://plato.stanford.edu/archives/ win2013/entries/hedonism/

Muehlhauser, Luke (2017). Report on Consciousness and Moral Patienthood. Open Philanthropy. Retrieved from https://www.openphilanthropy.org/2017-report-consciousness-and-moral-patienthood

Nagel, Thomas (1979). Mortal Questions. Cambridge University Press.

Nida-Rümelin, M. (2007). Grasping Phenomenal Properties. In Torin Alter and Sven Walter (Eds.), Phenomenal Concepts and Phenomenal Knowledge: New Essays on Consciousness and Physicalism (307-338). Oxford University Press. https://doi.org/10.1093/acpr of:oso/9780195171655.003.0013

Papineau, D. (2002). Thinking about Consciousness. Oxford University Press. https://doi. org/10.1093/0199243824.001.0001

Pereboom, Derk (2011). Consciousness and the Prospects of Physicalism. Oxford University Press. https://doi.org/10.1093/acprof:oso/9780199764037.001.0001

Rey, Georges (1995). Towards a Projectivist Account of Conscious Experience. In Thomas Metzinger (Ed.), Conscious Experience (123-144). Ferdinand Schoningh.

Rey, Georges (1997). A Question about Consciousness. In Ned Block, Owen Flanagan, and Güven Güzeldere (Eds.), The Nature of Consciousness (961-982). MIT Press.

Rorty, Richard (1965). Mind-Body Identity, Privacy and Categories. Review of MetaphysiCs, 19(1), 24-54.

Schroer, Robert (2010). Where's the Beef? Phenomenal Concepts as Both Demonstrative and Substantial. Australasian Journal of Philosophy, 88(3), 505-522. https://doi. org/10.1080/00048400903143861

Seager, William (2001). Consciousness, Value and Functionalism. Psyche, 7, 1-19.

Sebo, Jeff (2017). Agency and Moral Status. Journal of Moral Philosophy, 14(1), 1-22. https:// doi.org/10.1163/17455243-46810046

Shea, Nicholas (2014). Using Phenomenal Concepts to Explain away the Intuition of Contingency. Philosophical Psychology, 27(4), 553-570. https://doi.org/10.1080/09515 089.2012.730039

Shepherd, Joshua (2016). Moral Conflict in the Minimally Conscious State. In Walter Sinnott-Armstrong (Ed.), Finding Consciousness: The Neuroscience, Ethics, and Law of Severe Brain Damage (p-p). Oxford University Press. https://doi.org/10.1093/acprof:o so/9780190280307.003.0010

Sidgwick, Henry (1907). The Methods of Ethics (7th ed.). Thoemmes Press.

Siewert, Charles (1998). The Significance of Consciousness. Princeton University Press. https://doi.org/10.1515/9781400822720

Siewert, Charles (2014). Speaking Up For Consciousness. In Uriah Kriegel (Ed.), Current Controversies in Philosophy of Mind (199-221). Routledge. https://doi. org/10.4324/9780203116623-9

Singer, Peter (2011). Practical Ethics (3rd ed.). Cambridge University Press. https://doi. org/10.1017/CBO9780511975950

Sinhababu, Neil (2012). The Epistemic Argument for Hedonism. Unpublished manuscript. Retrieved from https://philpapers.org/archive/SINTEA-3.pdf

Sprigge, Timothy (1988). The Rational Foundations of Ethics. Routledge.

Strawson, Galen (2018, March 13). The Consciousness Deniers. New York Review of Books. Retrieved from https:/www.nybooks.com/daily/2018/03/13/the-consciousness-deniers/ 
Street, Sharon (2006). A Darwinian Dilemma for Realist Theories of Value. Philosophical Studies, 127(1), 109-166. https://doi.org/10.1007/s11098-005-1726-6

Streumer, Bart (2013). Can We Believe the Error Theory? Journal of Philosophy, 110(4), 194-212. https://doi.org/10.5840/jphil2013110431

Sturgeon, Scott (1994). The Epistemic View of Subjectivity. The Journal of Philosophy, 91(5), 221-235. https://doi.org/10.2307/2940751

Tännsjö, Torbjörn (1998). Hedonistic Utilitarianism. Edinburgh University Press.

van der Deijl, Willem (2019). Is Pleasure All That Is Good about Experience? Philosophical Studies, 171(7), 1769-1787. https://doi.org/10.1007/s11098-018-1090-y

Zimmerman, Michael (2015). Intrinsic vs. extrinsic value. In Edward N. Zalta (Ed.), The Stanford Encyclopedia of Philosophy (Spring 2015 ed.). Retrieved from https://plato. stanford.edu/archives/spr2015/entries/value-intrinsic-extrinsic/ 